\title{
Assessment of Forest Growing Stock of Timergara Forest Subdivision, Dir Lower Forest Division
}

\author{
Majid Ullah1, Amjad Ali Khan', Aamir Saleem1, Sajjad Saeed1, Umar Wahab² \\ ${ }^{1}$ Department of Forestry and Range Management, PMAS Arid Agriculture University, Rawalpindi, Pakistan \\ ${ }^{2}$ Department of Environmental Science, University of Haripur, Haripur, Pakistan \\ Email: "majidswati88@gmail.com
}

Received 8 September 2015; accepted 8 November 2015; published 11 November 2015

Copyright (C) 2015 by authors and Scientific Research Publishing Inc.

This work is licensed under the Creative Commons Attribution International License (CC BY).

http://creativecommons.org/licenses/by/4.0/

c. (i) Open Access

\begin{abstract}
The present study was aimed to assess the growing stock of Timergara forest subdivision which was a part of Dir lower forest division (Pakistan). The study area was divided into two different climatic zones (i.e. sub-tropical sub humid and sub-humid temperate zones) on the basis of altitudinal considerations. A total of 43 sample plots are taken in the forest area of 8480 hectare with random sampling technique representing $0.5 \%$ of the total forest area. Each sample plot size was of one hectare. In each $100 \times 100 \mathrm{~m}$ (1 ha plot), number of trees, diameter, age, height, increment, form factor and volume were measured. An interrelation between the diameter (independent variable) and all the other dependent variables (volume, increment and height) were found. At the end, volume tables were made which suited the local conditions as the ones used before were not suited to the local conditions.
\end{abstract}

\section{Keywords}

Growing Stock, Volume Tables, Sub Tropical, Sub Humid, Dependent Variables, Independent Variables

\section{Introduction}

Volume of all living trees having more than a certain diameter at breast height in a forest or wooded land is considered as growing stock. It is usually measured in cubic meters $\left(\mathrm{m}^{3}\right)$. It includes the stem from ground level or stump height up to a given top diameter, and may also include branches above a certain diameter [1]. Presently, about $5 \%$ of the country's land is under forest cover which is too much less if seen on internationally acceptable 
standard. But these too much short resources are also subject to extinction due to erosion, sedimentation and other disturbing processes. In spite of reclamation efforts, large areas remain plagued by these problems [2].

The assessment of growing stock means determining species composition, stocking and stand density, age, and size of trees. Stocking is the qualitative term which designates the relative occupation of the site by trees while stand density means degree of stem crowding within a stand.

Due to scarcity of forest resources, there is a need of very careful utilization of forests resources. We have to find a limit at which we can get benefits from the forests at present times as well as in the future. In order to find out the present condition of existing forest growing stock, forest inventories must be prepared periodically to find out the quantity of harvestable wood volume on sustained basis. The present study focuses on the assessment of the forest growing stock of Timergara forest subdivision, suggesting future management and preparation of local volume tables of dominant tree species which suit the local conditions for future sustainable management of the regional forest.

\section{Materials and Methods}

The present study was conducted in Timergara forest subdivision of Dir lower forest division. The area had once vigorous vegetation but now, the vegetation is very poor due to human interruption and disturbances as well as natural phenomenon. Temperature of the area varies considerably during different months of the year and during the same months at different localities of the area. The average minimum temperature at Timergara in December is $5.2^{\circ} \mathrm{C}$ and mean maximum in July is $35.8^{\circ} \mathrm{C}$ at the same station. The average annual rainfall at Dir and Timergara is $1431 \mathrm{~mm}$ and $685 \mathrm{~mm}$ respectively. Dir and Barawal valleys receive maximum precipitation in the form of snow during winter. Snow generally starts at the end of November on the upper reaches and descends downwards as the temperature falls in winter [3].

The forests growing stock is assessed through different methods. As assessing growing stock is of a simple and easy process, there are several methods for its calculation. About all the methods varies from the other in one way or the other. Some of the methods used by different peoples in different times are the following.

The volume of forest growing stock has been estimated using auxiliary information derived from relay scope or ocular assessment [4]. The floristic composition, structure and natural regeneration have been studied in three $50 \times 50 \mathrm{~m}$ plot each in undisturbed, disturbed-invaded and disturbed forests [5]. Tree species diversity and floristic composition of a tropical seasonal rainforest was found which is based on a census of all trees with diameter at breast height [6]. Applied statistical and geostatistical analysis was used to analyze the regeneration diversity and the spatial distribution of the regeneration of tree species in natural forests [7]. The variable relationship between tree age and diameter at breast height for natural forests using eight fir-coniferous and broad-leaved mixed stands plots [8]. The determination of the structural composition of a deforested area of Chittagong, Bangladesh based on diameter and height class distribution [9]. The relationship between tree height and diameter has been studied by Chong [10]. They prepared individual tree height-diameter curves of larch-spruce-fir forests to predict the height of the individual tree from diameter at breast height. Similarly [11], used sampling technique for making stand inventory. The accuracy and precision of stand-level inventory were found to be moderate, although the costs and time spent in field work were considered to be fairly high. Systematic sampling technique was used for the analysis of vegetation of the forest and to describe the structural and floral composition of the vegetation [12]. The regeneration, density and size class distribution of trees was found through the use of permanent sample plots [13].

Keeping in mind all the above methods, Random sampling technique was used to select sample plots. The sample plots were taken in a way that they were the true representative of the whole forest, i.e. plot had trees of all age classes and had the major species present in the forest. The total forest area of 8480 hectare was sampled with a sampling intensity of $0.5 \%$, [14]. Thus in total of 43 plots were taken according to the decided strategy. All plots were of one hectare. Then total number trees/plots, total number of species/plot, trees diameter, tree height, trees age and trees increment were done for all the plots.

\section{Results and Discussions}

Results indicated that there are mainly two tree species in the study area, i.e. Chirpine and Kail. Chirpine was distributed over the whole study area while Kail was confined only to Rabat. Chirpine is the leading tree species of the area with a composition of $50.33 \%$ followed by Kail with a composition of $44.03 \%$ while the presence of 
other species (Quercus, Eucalyptus) was 5.6\%. The location wise composition of species was also determined. The results showed that Kail is the leading specie of Rabat, i.e. $64.5 \%$ followed by Chirpine with a composition of $35.5 \%$. Talash is covered mostly by Chirpine with a composition of $88 \%$ while other miscellaneous trees cover about $12 \%$ area. Asbanr is also covered by Chirpine, i.e. $80 \%$ while the remaining $20 \%$ is covered by Quercus and other species. Results show that Chirpine is the most dominant specie of the area followed by Kail.

Tree density data showed that highest tree density is in Rabat which was 27.27 trees/ha, and the lowest was that of Talash which was 8.5 trees/ha while in Asbanr, it was 17.125 trees/ha. The overall tree density was found to be 33.33 trees/ha. Species wise tree density showed that the highest tree density was that of Chirpine (20.79 trees/ha) and the lowest was that of Quercus (1.83 trees/ha) while that of Kail was 18.18 trees/ha.

The relationship between tree diameters at breast height (dbh) was also found out which showed that there is a highly significant inverse relationship between tree diameter at breast height (dbh) and tree density. This indicated that the tree density decreases with an increase in tree diameter. So this is very important to reduce number of trees per unit area for healthy growth of forest crop so that trees can grow in diameter.

The forest growing stock data was collected from the three sites with respect to their densities. The denser area was that of Rabat followed by Asbanr while Talash has lesser density. The species wise density shows that Chirpine has the highest tree density (20.79 trees/ha) followed by Kail (18.18 trees/ha) while other miscellaneous species have very low density (1.83 trees/ha).

Frequency (the number of occurrence of different species in the area) was also found out. The data collected from all the sampling area showed that Chirpine was the most frequent specie (55.09) followed by Kail (41.70) while other miscellaneous tree species (e.g. Quercus spp. etc) has a very low frequency (3.75).

The overall data shows that average crop height is $15.04 \mathrm{~m}$. The specie wise tree heights showed that Chirpine tree has the maximum tree height i.e. $15.5 \mathrm{~m}$ while the average height of Kail is $14.48 \mathrm{~m}$. The height data of all the trees was compared with the diameter. The data showed a positive relationship between the two which means that height of the trees increase with an increase in diameter of the trees. Although, after a certain period i.e. after completing the rotation period or near it, the relationship may not remain the same and there may occur some variations. But up to large extent, there remains a positive relationship between the height and diameter of the tree.

Increment of all the trees falling in the sample plots was found. This was found out through dividing the length of woody core by 10 (year). These increments were arranged according to the diameter class which ranges from $20-86 \mathrm{~cm}$. The overall data showed that average diameter at breast height point (dbh) is $32.186 \mathrm{~cm}$. The specie wise trees diameter shows that Kail tree show the maximum tree height i.e. $32.33 \mathrm{~cm}$ while the average height of Chirpine is $32.05 \mathrm{~cm}$. The overall increment data was compared with the diameter of the trees. The comparison showed a negative relationship between the two, i.e. the increment decrease with an increase in diameter/age. This is clear in Figure 1 and Figure 2. This means that more increment occurs in trees of smaller diameter/less age while less increment occurs in trees of more diameter.

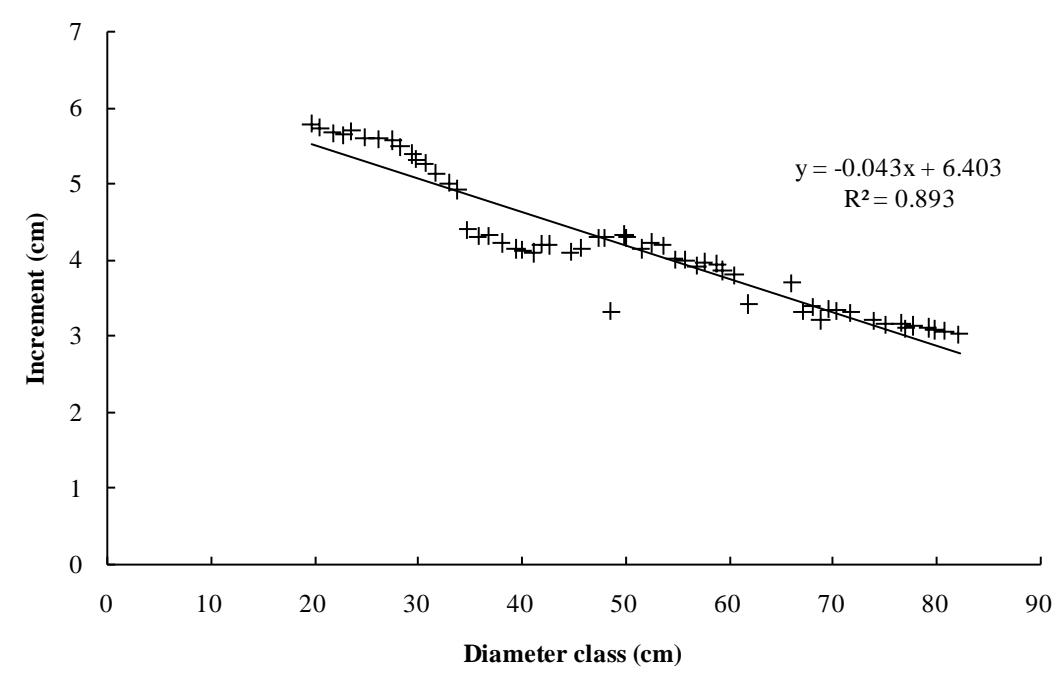

Figure 1. Fitted lines between diameter and Increment of Pinus rhoxburghii. 
Table 1. Volume table of Pinus roxburghii.

\begin{tabular}{|c|c|c|c|c|c|c|c|c|}
\hline $\begin{array}{c}\text { DBH } \\
\text { class }(\mathbf{c m})\end{array}$ & Mean dbh (cm) & Mean dbh (m) & $\mathbf{D}^{2}$ & $\begin{array}{c}\text { Average } \\
\text { height (m) }\end{array}$ & Form factor & Volume $\mathrm{m}^{3} /$ tree & $\begin{array}{l}\text { No. of existing } \\
\text { trees/ha }\end{array}$ & $\begin{array}{c}\text { Total volume } \\
\mathbf{m}^{3} / \mathbf{h a}\end{array}$ \\
\hline 20 & 19.71 & 0.1971 & 0.038 & 11.1 & 0.488 & 0.157 & 0.48 & 0.075 \\
\hline 21 & 20.6 & 0.206 & 0.042 & 13.24 & 0.449 & 0.19 & 0.93 & 0.176 \\
\hline 22 & 21.81 & 0.2181 & 0.047 & 12.17 & 0.43 & 0.188 & 0.62 & 0.116 \\
\hline 23 & 22.9 & 0.229 & 0.052 & 12.2 & 0.41 & 0.205 & 1.2 & 0.246 \\
\hline 24 & 23.63 & 0.236 & 0.055 & 12.55 & 0.41 & 0.221 & 1.13 & 0.249 \\
\hline 25 & 24.91 & 0.249 & 0.062 & 12.75 & 0.4 & 0.249 & 1.34 & 0.33 \\
\hline 26 & 26.2 & 0.262 & 0.068 & 12.82 & 0.4 & 0.271 & 1.16 & 0.314 \\
\hline 27 & 27.6 & 0.276 & 0.076 & 13.41 & 0.4 & 0.268 & 1.51 & 0.4 \\
\hline 28 & 28.31 & 0.283 & 0.08 & 13.39 & 0.4 & 0.337 & 1.32 & 0.444 \\
\hline 29 & 29.51 & 0.295 & 0.087 & 13.05 & 0.39 & 0.346 & 1.44 & 0.498 \\
\hline 30 & 29.92 & 0.299 & 0.089 & 16.092 & 0.39 & 0.439 & 0.3 & 0.13 \\
\hline 31 & 30.7 & 0.307 & 0.094 & 16.71 & 0.38 & 0.463 & 0.48 & 0.222 \\
\hline 32 & 31.81 & 0.318 & 0.1011 & 17.41 & 0.38 & 0.522 & 0.34 & 0.1774 \\
\hline 33 & 32.96 & 0.329 & 0.108 & 17.17 & 0.38 & 0.554 & 0.62 & 0.343 \\
\hline 34 & 33.9 & 0.339 & 0.114 & 17.68 & 0.37 & 0.588 & 0.58 & 0.341 \\
\hline 35 & 34.8 & 0.348 & 0.121 & 17.42 & 0.37 & 0.612 & 0.9 & 0.55 \\
\hline 36 & 35.81 & 0.358 & 0.128 & 18.32 & 0.37 & 0.677 & 0.86 & 0.582 \\
\hline 37 & 36.9 & 0.369 & 0.136 & 17.71 & 0.36 & 0.675 & 0.83 & 0.56 \\
\hline 38 & 38.1 & 0.381 & 0.145 & 18.17 & 0.36 & 0.739 & 0.9 & 0.665 \\
\hline 39 & 39.5 & 0.395 & 0.156 & 18.6 & 0.36 & 0.82 & 1.2 & 0.984 \\
\hline 40 & 40.12 & 0.401 & 0.16 & 18.262 & 0.36 & 0.828 & 0.06 & 0.049 \\
\hline 41 & 41.12 & 0.411 & 0.168 & 18.17 & 0.36 & 0.856 & 0.023 & 0.0196 \\
\hline 42 & 41.93 & 0.419 & 0.175 & 18 & 0.36 & 0.887 & 0.023 & 0.02 \\
\hline 43 & 42.68 & 0.426 & 0.181 & 23 & 0.35 & 1.14 & 0.023 & 0.026 \\
\hline 45 & 44.76 & 0.447 & 0.199 & 20 & 0.35 & 1.092 & 0.06 & 0.065 \\
\hline 46 & 45.83 & 0.458 & 0.209 & 20.3 & 0.35 & 1.165 & 0.046 & 0.053 \\
\hline 47 & 47.39 & 0.473 & 0.223 & 20.98 & 0.35 & 1.28 & 0.046 & 0.058 \\
\hline 48 & 48.13 & 0.481 & 0.231 & 21 & 0.34 & 1.29 & 0.046 & 0.059 \\
\hline 49 & 48.67 & 0.486 & 0.236 & 21.005 & 0.34 & 1.32 & 0.139 & 0.183 \\
\hline 50 & 49.92 & 0.499 & 0.249 & 22.83 & 0.34 & 1.513 & 0.116 & 0.175 \\
\hline 51 & 50.16 & 0.501 & 0.251 & 23.26 & 0.34 & 1.55 & 0.279 & 0.43 \\
\hline 52 & 51.58 & 0.515 & 0.265 & 22.2 & 0.34 & 1.56 & 0.116 & 0.18 \\
\hline 53 & 52.55 & 0.525 & 0.275 & 22.17 & 0.34 & 1.62 & 0.116 & 0.187 \\
\hline 54 & 53.65 & 0.535 & 0.287 & 23.18 & 0.34 & 1.77 & 0.255 & 0.45 \\
\hline 55 & 54.78 & 0.547 & 0.299 & 22.8 & 0.34 & 1.81 & 0.162 & 0.293 \\
\hline 56 & 55.79 & 0.557 & 0.31 & 22.55 & 0.33 & 1.8 & 0.511 & 0.919 \\
\hline 57 & 56.94 & 0.569 & 0.323 & 23.75 & 0.33 & 1.98 & 0.279 & 0.552 \\
\hline 58 & 57.66 & 0.576 & 0.331 & 22.52 & 0.33 & 1.92 & 0.069 & 0.132 \\
\hline
\end{tabular}




\section{Continued}

\begin{tabular}{|c|c|c|c|c|c|c|c|c|}
\hline 59 & 58.91 & 0.589 & 0.345 & 23.96 & 0.33 & 2.13 & 0.046 & 0.097 \\
\hline 60 & 59.43 & 0.594 & 0.352 & 24.43 & 0.31 & 2.09 & 0.023 & 0.048 \\
\hline 61 & 60.53 & 0.605 & 0.366 & 24.505 & 0.31 & 2.18 & 0.046 & 0.1 \\
\hline 62 & 61.94 & 0.619 & 0.383 & 24.63 & 0.3 & 2.21 & 0.023 & 0.0508 \\
\hline 66 & 66.12 & 0.661 & 0.436 & 23.9 & 0.3 & 2.45 & 0.046 & 0.1127 \\
\hline 67 & 67.22 & 0.672 & 0.451 & 24.12 & 0.3 & 2.56 & 0.046 & 0.1177 \\
\hline 68 & 68.11 & 0.681 & 0.463 & 23.88 & 0.3 & 2.6 & 0.093 & 0.241 \\
\hline 69 & 68.93 & 0.689 & 0.474 & 24.215 & 0.3 & 2.7 & 0.046 & 0.124 \\
\hline 70 & 69.74 & 0.697 & 0.485 & 25.13 & 0.29 & 2.76 & 0.046 & 0.126 \\
\hline 71 & 70.5 & 0.705 & 0.497 & 24.5 & 0.29 & 2.77 & 0.046 & 0.127 \\
\hline 72 & 71.8 & 0.718 & 0.515 & 25.76 & 0.29 & 3.01 & 0.023 & 0.069 \\
\hline 74 & 73.96 & 0.739 & 0.546 & 25.81 & 0.29 & 3.2 & 0.139 & 0.444 \\
\hline 75 & 75.13 & 0.751 & 0.564 & 25.525 & 0.28 & 3.15 & 0.023 & 0.072 \\
\hline 76 & 76.66 & 0.766 & 0.586 & 26.875 & 0.28 & 3.461 & 0.069 & 0.24 \\
\hline 77 & 77.12 & 0.771 & 0.594 & 24.91 & 0.28 & 3.25 & 0.023 & 0.074 \\
\hline 78 & 77.87 & 0.778 & 0.605 & 25.06 & 0.27 & 3.2 & 0.023 & 0.073 \\
\hline 79 & 79.29 & 0.792 & 0.627 & 24.575 & 0.27 & 3.264 & 0.023 & 0.075 \\
\hline 80 & 79.89 & 0.798 & 0.636 & 24.82 & 0.27 & 3.34 & 0.023 & 0.076 \\
\hline 81 & 80.84 & 0.808 & 0.652 & 25.05 & 0.27 & 3.46 & 0.023 & 0.079 \\
\hline 82 & 82.25 & 0.822 & 0.675 & 26.1 & 0.27 & 3.72 & 0.023 & 0.0736 \\
\hline
\end{tabular}

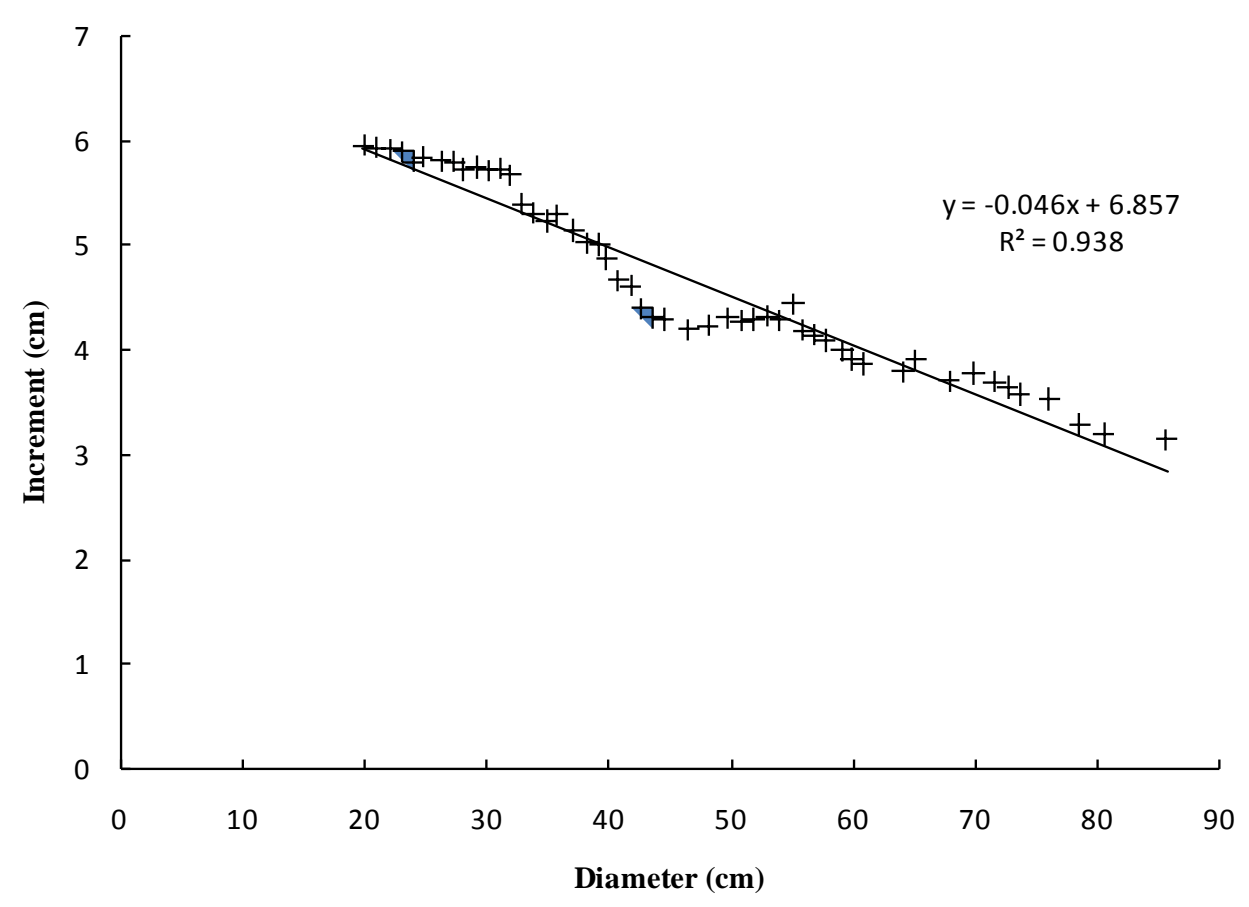

Figure 2. Fitted lines between diameter and increment of Pinus wallichiana. 
Table 2. Volume table of Pinus wallichiana.

\begin{tabular}{|c|c|c|c|c|c|c|c|c|}
\hline $\begin{array}{l}\text { DBH class } \\
\text { (cm) }\end{array}$ & $\begin{array}{c}\text { Mean DBH } \\
\text { (cm) }\end{array}$ & $\begin{array}{c}\text { Mean DBH } \\
\text { (m) }\end{array}$ & $\mathbf{D}^{2}$ & $\begin{array}{l}\text { Average height } \\
\text { (m) }\end{array}$ & Form factor & $\begin{array}{l}\text { Volume } \\
\mathrm{m}^{3} / \text { tree }\end{array}$ & No. of trees/ha & $\begin{array}{c}\text { Total volume } \\
\mathbf{m}^{3} / \mathbf{h a}\end{array}$ \\
\hline 20 & 19.9 & 0.199 & 0.039 & 10.37 & 0.59 & 0.18 & 0.9 & 0.162 \\
\hline 21 & 20.87 & 0.208 & 0.043 & 10.67 & 0.59 & 0.2 & 0.93 & 0.186 \\
\hline 22 & 22.13 & 0.221 & 0.048 & 11.65 & 0.59 & 0.25 & 0.76 & 0.19 \\
\hline 23 & 23.1 & 0.231 & 0.053 & 12.12 & 0.58 & 0.288 & 1.02 & 0.29 \\
\hline 24 & 23.95 & 0.239 & 0.057 & 12.602 & 0.58 & 0.326 & 0.95 & 0.309 \\
\hline 25 & 24.71 & 0.247 & 0.061 & 12.05 & 0.58 & 0.328 & 0.69 & 0.226 \\
\hline 26 & 26.21 & 0.262 & 0.068 & 13.57 & 0.58 & 0.417 & 0.97 & 0.404 \\
\hline 27 & 27.31 & 0.273 & 0.073 & 13.25 & 0.57 & 0.43 & 1.51 & 0.64 \\
\hline 28 & 28.12 & 0.281 & 0.078 & 13.35 & 0.57 & 0.464 & 1.11 & 0.51 \\
\hline 29 & 29.1 & 0.291 & 0.084 & 14.29 & 0.56 & 0.52 & 1.46 & 0.75 \\
\hline 30 & 30.09 & 0.3 & 0.09 & 16.9 & 0.56 & 0.66 & 0.44 & 0.29 \\
\hline 31 & 31.03 & 0.31 & 0.096 & 16.71 & 0.56 & 0.7 & 0.32 & 0.224 \\
\hline 32 & 31.94 & 0.319 & 0.101 & 16.93 & 0.56 & 0.74 & 0.44 & 0.325 \\
\hline 33 & 32.88 & 0.328 & 0.107 & 17.1 & 0.56 & 0.79 & 0.6 & 0.474 \\
\hline 34 & 33.81 & 0.338 & 0.114 & 17.34 & 0.55 & 0.84 & 0.39 & 0.327 \\
\hline 35 & 34.89 & 0.348 & 0.121 & 17.6 & 0.55 & 0.9 & 0.58 & 0.522 \\
\hline 36 & 35.8 & 0.358 & 0.128 & 18.29 & 0.55 & 1.005 & 0.53 & 0.532 \\
\hline 37 & 37.13 & 0.371 & 0.137 & 18.35 & 0.55 & 1.07 & 0.88 & 0.49 \\
\hline 38 & 38.19 & 0.381 & 0.145 & 18.31 & 0.54 & 1.11 & 0.69 & 0.76 \\
\hline 39 & 39.25 & 0.392 & 0.153 & 19.2 & 0.54 & 1.25 & 0.86 & 1.075 \\
\hline 40 & 39.81 & 0.398 & 0.158 & 18.75 & 0.54 & 1.255 & 0.162 & 0.2 \\
\hline 41 & 40.75 & 0.407 & 0.165 & 18.08 & 0.53 & 1.23 & 0.023 & 0.028 \\
\hline 42 & 41.78 & 0.417 & 0.173 & 18.35 & 0.53 & 1.31 & 0.116 & 0.15 \\
\hline 43 & 42.72 & 0.427 & 0.182 & 18.5 & 0.53 & 1.39 & 0.069 & 0.095 \\
\hline 45 & 43.61 & 0.436 & 0.19 & 17.94 & 0.53 & 1.41 & 0.023 & 0.32 \\
\hline 46 & 44.5 & 0.445 & 0.198 & 18.64 & 0.52 & 1.5 & 0.069 & 0.1035 \\
\hline 47 & 46.5 & 0.465 & 0.216 & 15.5 & 0.52 & 1.36 & 0.069 & 0.082 \\
\hline 48 & 48.12 & 0.481 & 0.231 & 15 & 0.52 & 1.41 & 0.116 & 0.163 \\
\hline 49 & 49.73 & 0.497 & 0.247 & 19 & 0.52 & 1.9 & 0.116 & 0.22 \\
\hline 50 & 50.9 & 0.509 & 0.259 & 23.075 & 0.51 & 2.38 & 0.16 & 0.38 \\
\hline 51 & 51.86 & 0.518 & 0.268 & 21.85 & 0.51 & 2.34 & 0.139 & 0.32 \\
\hline 52 & 53.02 & 0.53 & 0.28 & 23.16 & 0.5 & 2.53 & 0.116 & 0.29 \\
\hline 53 & 54.01 & 0.54 & 0.291 & 22.2 & 0.5 & 2.53 & 0.139 & 0.35 \\
\hline 54 & 55.11 & 0.551 & 0.303 & 22.65 & 0.5 & 2.68 & 0.093 & 0.24 \\
\hline 55 & 55.93 & 0.559 & 0.312 & 23.17 & 0.49 & 2.77 & 0.116 & 0.32 \\
\hline 56 & 56.78 & 0.567 & 0.321 & 23 & 0.49 & 2.82 & 0.2 & 0.56 \\
\hline 57 & 57.73 & 0.577 & 0.332 & 24.32 & 0.48 & 3.03 & 0.069 & 0.209 \\
\hline 58 & 59.14 & 0.591 & 0.349 & 21.88 & 0.48 & 2.86 & 0.023 & 0.065 \\
\hline 59 & 59.92 & 0.599 & 0.358 & 20 & 0.47 & 2.64 & 0.046 & 0.12 \\
\hline 60 & 60.81 & 0.608 & 0.369 & 22 & 0.47 & 2.98 & 0.023 & 0.068 \\
\hline 61 & 64.11 & 0.641 & 0.41 & 25.5 & 0.46 & 3.76 & 0.069 & 0.259 \\
\hline 62 & 65.17 & 0.651 & 0.423 & 22 & 0.45 & 3.28 & 0.023 & 0.075 \\
\hline 66 & 67.9 & 0.679 & 0.461 & 23.47 & 0.45 & 3.81 & 0.023 & 0.087 \\
\hline 67 & 69.9 & 0.699 & 0.488 & 24.95 & 0.45 & 4.3 & 0.046 & 0.197 \\
\hline 68 & 71.63 & 0.716 & 0.512 & 24.13 & 0.45 & 4.35 & 0.069 & 0.3 \\
\hline 69 & 72.71 & 0.727 & 0.528 & 24 & 0.42 & 4.17 & 0.069 & 0.287 \\
\hline 70 & 73.68 & 0.736 & 0.54 & 23.5 & 0.42 & 4.175 & 0.023 & 0.096 \\
\hline 71 & 76.09 & 0.76 & 0.577 & 28 & 0.42 & 5.31 & 0.023 & 0.122 \\
\hline 72 & 78.6 & 0.786 & 0.617 & 27 & 0.41 & 5.35 & 0.023 & 0.123 \\
\hline 74 & 80.6 & 0.806 & 0.649 & 27.05 & 0.41 & 5.64 & 0.023 & 0.129 \\
\hline 75 & 85.71 & 0.857 & 0.73 & 27.65 & 0.4 & 6.08 & 0.023 & 0.139 \\
\hline
\end{tabular}


The age of all the dominant tree species was found with the help of annual rings counting. The rings were mostly visible through naked eye. But in some cases, if the rings were not clearly visible, magnifying glass was used to see the rings. The ages of different species varied significantly from each other. The ages of sampled trees of different species showed that the ages of trees of Pinus rhoxburghii ranges from 5 - 94 years while the ages of sampled trees of Pinus wallichiana had an average age range of 10 - 96 years.

On the bases of all the data collected, volume of all the individual trees as well as that of the trees of all age classes was also found out. This volume and all the other data is used to make volume tables (Table 1 and Table 2) for the species present in the area.

\section{Conclusion}

The results of the study showed that the study area had once very dense vegetation but presently, the vegetation was very poor and sparse. There were no much mature trees. The trees were mostly immature. The reason for this was the different disturbing factors, i.e. human beings, animals grazing and other human related disturbing factors. Last but not the least, poor management was also a main reason for the poor vegetation. Due to these reasons, the regeneration in the area was also negligible. There was a need of plantation campaigns and awareness in the people to save and improve the vegetation in the area.

\section{References}

[1] FAO (2010) Global Forest Resources Assessment, Food and Agriculture Organization of the United Nations, Pakistan. Working Paper 144/E, Rome, Italy. www.fao.org/forestry/fra

[2] Sheikh, M.I. and Hafeez, S.M. (1997) Forest and Forestry in Pakistan. A-One Publisher Urdu Bazar, Lahore, 151-160.

[3] Khan, M.I. (2008) Land Covers Assessment through GIS and RS in Lower Dir. MSC Thesis, Pakistan Forest Institute, Peshawar.

[4] Corona, P., Fattorini, L. and Franceschi, S. (2009) Estimating the Volume of Forest Growing Stock Using Auxiliary Information Derived from Relascope or Ocular Assessments. Forest Ecology and Management, 257, 2108-2114. http://dx.doi.org/10.1016/j.foreco.2009.02.017

[5] Addo-Fordjour, P., Obeng, S., Anning, A.K. and Addo, M.G. (2009) Floristic Composition, Structure and Natural Regeneration in a Moist Semi-Deciduous Forest Following Anthropogenic Disturbances and Plant Invasion. Int. J. of Biodiversity and Cons., 1, 21-37.

[6] Lu, X.T., Yin, J.X. and Tang, J.W. (2010) Structure, Tree Species Diversity and Composition of Tropical Seasonal Rainforests. Journal of Tropical Forest Science, 22, 260-270.

[7] Gebrihiwot, M. (2003) Assessment of Natural Regeneration Diversity and Distribution of Forests Tree Species. A Case Study on Wondo-Wesha Catchment Awassa Watershed Southern Ethiopia. International Institute for Geo, Information Science and Earth Observation, Enscheda, Netherlands, 10-23.

[8] Hu, Y.Y., Kang, X.G. and Zhao, J.H. (2009) Variable Relationship between Tree Age and Diameter at Breast Height for Natural Forests in Changbai Mountains. Journal of Northeast Forestry, 37, 38-42.

[9] Al-Amin, M., Alamgir, M. and Bhuiyan, M.A.R. (2005) Structural Composition Based on Diameter and height Class Distribution of a Deforested Area of Chittagong, Bangladesh. Journal of Applied Sciences, 5, 227-231.

[10] Zeng, C., Lei, X.D., Liu, X.Z., Zhao, L.W. and Yang, Y.J. (2009) Individual Tree Height Diameter Curves of Larch Spruce Fir Forests. Forest Research, 22, 182-189.

[11] Haara (2005) The Uncertainty of Forest Management Planning Data in Finnish Nonindustrial Private Forestry. Faculty of Forestry, University of Joensuu, Finlaland, 40.

[12] Pandey, S. and Bajracharya, S.B. (2010) Vegetation Composition and Biomass Production in Community Forest in Sikre VDC Adjoining Shivapuri National Park, Kathmandu. Nepal Journal of Science and Technology, 11, 133-138.

[13] Omeja, P., Obua, J. and Cunningham, A.B. (2004) Regeneration, Density and Size Class Distribution of Tree Species Used for Drum Making in Central Uganda. African Journal of Ecology, 42, 129-136.

[14] Arfeen, R.Z. (2009) Growth and Increment Evaluation of Pinus roxburghii in Ghoragali Forest Subdivision, Murree Pakistan. M. Phil Thesis, PMAS AAU, Rawalpindi. 